\title{
Growth Retardation at Different Stages of Bean Seedlings Developed from Seeds Exposed to Synchrotron X-Ray Beam
}

\author{
Sonal Dhamgaye ${ }^{1}$, Vishal Dhamgaye ${ }^{2}$, Rekha Gadre ${ }^{1^{*}}$ \\ ${ }^{1}$ School of Biochemistry, Devi Ahilya University, Takshashila Campus, Indore, India \\ ${ }^{2}$ Indus Synchrotrons Utilisation Division, Raja Ramanna Centre for Advanced Technology, Indore, India \\ Email: *rekhagadre29@gmail.com
}

How to cite this paper: Dhamgaye, S., Dhamgaye, V. and Gadre, R. (2018) Growth Retardation at Different Stages of Bean Seedlings Developed from Seeds Exposed to Synchrotron X-Ray Beam. Advances in Biological Chemistry, 8, 29-35.

https://doi.org/10.4236/abc.2018.82003

Received: January 25, 2018

Accepted: April 8, 2018

Published: April 11, 2018

Copyright $\odot 2018$ by authors and Scientific Research Publishing Inc. This work is licensed under the Creative Commons Attribution International License (CC BY 4.0).

http://creativecommons.org/licenses/by/4.0/

\begin{abstract}
Irradiated seeds of Phaseolus vulgaris cv. Rajmah using Synchroton X-Ray Beam (BL-07) at RRCAT, Indore at various doses in the range of $0.5-10 \mathrm{~Gy}$ were used to raise the seedling and the growth status at different stages was evaluated. Prior to germination, in the seeds soaked for 24 hours, the water regain remained unaffected by seed irradiation at $1-10$ Gy doses, while the acid phosphatase activity was significantly reduced. Strong correlation $\left(\mathrm{R}^{2}=\right.$ 0.685) between irradiation dose and enzyme activity also resulted. Analysing seed irradiation effect on seed development up to 4 days, \% germination, germination index (GI), seedling wt, and seedling vigour were non significantly decreased at 5.0 Gy dose. The overall growth of 10 days old seedlings raised from irradiated seeds was substantially reduced at irradiation doses of 2 and 5 Gy exerting strong -ve correlation. Also \% germination and seed vigour index (SVI) were prominently decreased due to seed irradiation. The nitrogen status of the seedlings, reflected by nitrate reductase activity (NRA) was significantly reduced in response to irradiation exerting strong correlation. The results demonstrate decreased phosphate mobilization in soaked seeds, time dependent decreased growth being more substantial with longer duration and reduced nitrate assimilation due to seed irradiation with Synchroton X-Ray Beam.
\end{abstract}

\section{Keywords}

Synchroton Radiation, Growth Effects, Phaseolus vulgaris, Nitrate Assimilation

\section{Introduction}

Ionising radiation occurs naturally and the plants are exposed to different types 
of radiation in the terrestrial environment. Significant sources of variation in radiation include altitude, relative abundance of radioactive isotopes in soils and nuclear accidents. Plant exposure to ionizing radiations in the vicinity of nuclear accidents to influence growth and development has been reported [1]. Phaseolus vulgaris (French bean or common bean) is an important and popular legume crop grown for green vegetable and dry seeds. It is valued for its high protein content $(23 \%)$ and is also rich in calcium, phosphorus and iron. Growth and development of the plants is initiated with germination of the seeds. Use of reserve nutrients of seeds during germination plays a key role in growth. Thus, phosphate mobilization involving acid phosphatase is of importance, as it is induced with germination [2] [3]. Nitrogen is one of the limiting nutrients for the plant growth and development, with assimilatory nitrate reduction as an important process for its utilization. Nitrate reductase (NR, EC 1.6.6.1), the key enzyme of this pathway, is substrate inducible being regulated by a number of nutritional and environmental factors [4]. Further, NR is often correlated with the overall nitrogenous status of the system and has been reported to be involved in the synthesis of a signaling molecule, nitric oxide (NO) [5]. Although reduced leaf growth parameters, such as leaf area, dry mass, pigment content etc. upon irradiation of dwarf bean plants to $\mathrm{x}$-radiations, have been reported [6], the synchroton $\mathrm{x}$-ray irradiation affecting growth has not been reported yet. In this study, the effect of x-ray exposure of Phaseolus vulgaris seeds on phosphate mobilization in soaked seeds, overall growth and nitrate assimilation in seedlings has been studied. The seeds were exposed to various energies at BL-07, Indus-2 for monitoring the effects.

\section{Material and Methods}

Seeds of Phaseolus vulgaris cv. Rajmah purchased from Pahuja Seeds, New Delhi were irradiated by using Indus-2 Synchroton X Ray Beam (BL-07) at RRCAT, Indore in the dose range of 0.5 - $10 \mathrm{~Gy}$. The $\mathrm{x}$-ray lithography beam line (BL-07) is primarily used for $\mathrm{x}$-ray irradiation of polymer samples for microfabrication purpose [7]. As shown in Figure 1, for seed irradiation total 100 seeds were packaged without any overlapping in polythene bag of size $30 \mathrm{~mm} \times 50 \mathrm{~mm}$ and exposed to $\mathrm{x}$ radiations in air and at room temperature $\sim 25^{\circ} \mathrm{C}$ using $6-11 \mathrm{keV}$ $\mathrm{x}$-ray energy range.

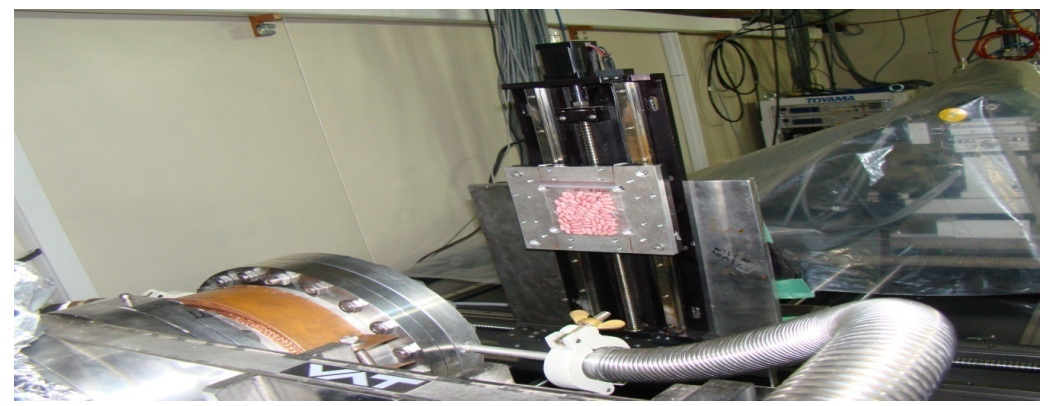

Figure 1. Photograph showing seed irradiation method. 
Irradiated seeds were surface sterilized with $0.1 \% \mathrm{HgCl}_{2}$ for 1 - 2 minutes followed by thorough washing with distilled water. To evaluate the effects of irradiation, the seedlings were raised in petri plates for 4 days or in plastic pots containing acid washed sand for 10 days in continuous light supplied by fluorescent tubes. Seedlings from respective doses were used for analysis of various growth parameters, such as, \% germination, seedling wt, root and shoot length and root and leaf wt. Percent germination was calculated by the formula

$$
\% G=\frac{\text { Number of seeds germinated }}{\text { Total number of seeds }} \times 100
$$

Weight measurements were carried out by using electronic balance and lengths were measured with $\mathrm{cm}$ scale. Water regain was calculated as

$$
\text { Water regain }=\frac{\text { Weight of soaked seeds }- \text { Weight of dry seeds }}{\text { Weight of dry seeds }}
$$

Acid phosphatase activity in the soaked seeds was extracted and assayed by measuring p-nitrophenol (PNP) spectrophotometrically at $410 \mathrm{~nm}$ according to the method of Prazeres et al. [2]. Whole seedling sample was homogenized in 5 $\mathrm{ml}$ of $0.1 \mathrm{M}$ sodium acetate buffer $(\mathrm{pH} 5)$ in cold room. The homogenate was centrifuged at $10,000 \times \mathrm{g}$ using "REMI C-24 Plus" at $4^{\circ} \mathrm{C}$ for $20 \mathrm{~min}$. The reaction mixture in final volume of $2 \mathrm{ml}$ containing $100 \mathrm{mM}$ sodium acetate buffer ( $\mathrm{pH}$ 5), $5 \mathrm{mM}$ PNPP as substrate and enzyme was incubated at $37^{\circ} \mathrm{C}$ for $5 \mathrm{~min}$ and $1 \mathrm{ml}$ of $1 \mathrm{M} \mathrm{NaOH}$ was added to the reaction mixture. The amount of p-nitro phenol (PNP) released was estimated by measuring absorbance $405 \mathrm{~nm}$ using a double beam spectrophotometer "Shimadzu UV-1800". The enzyme activity was expressed as $\mu$ moles PNP $\min ^{-1} \mathrm{~g}^{-1}$ fr wt and $\mu$ moles PNP $\min ^{-1} \mathrm{mg}^{-1}$ protein. The activity of enzyme was calculated by using a standard series of p-nitro phenol in the range of 0.02 to $0.2 \mu$ moles prepared in similar manner.

In vivo NRA of the leaf material was assayed by colorimetric estimation of nitrite by the method of Srivastava [8]. Whole shoot/root system of the seedling was cut into small segments and suspended in $10.0 \mathrm{ml}$ of incubation mixture (composed of $8.0 \mathrm{ml}$ of $0.1 \mathrm{M}$ phosphate buffer, $\mathrm{pH} 7.4 ; 1.0 \mathrm{ml}$ of $0.2 \mathrm{M} \mathrm{KNO}_{3}$ and $1.0 \mathrm{ml}$ of $25 \%$ isopropanol) inside a tightly stoppered dark vial. The reaction mixture was incubated in dark for $30 \mathrm{~min}$ at $30^{\circ} \mathrm{C}$. After incubation the mixture was decanted and assayed for nitrite content. For this, $2.0 \mathrm{ml}$ of acidic sulphanilamide $(1 \%$ in $1 \mathrm{~N} \mathrm{HCl})$ was added to $2.0 \mathrm{ml}$ of the incubation medium followed by addition of $2.0 \mathrm{ml} \mathrm{NED} \mathrm{(0.02 \%} \mathrm{in} \mathrm{distilled} \mathrm{water).} \mathrm{After} 10$ minutes, developed pink colour was read for absorbance at $540 \mathrm{~nm}$ using a double beam spectrophotometer "Shimadzu UV-1800". The enzyme activity was expressed as nmoles of nitrite formed $\mathrm{h}^{-1} \mathrm{~g}^{-1} \mathrm{fr}$. wt. Nitrite content was calculated by using a standard series of $\mathrm{NaNO}_{2}$ (10 to 100 nmoles) prepared in a similar manner.

Results expressed are the average values of at least three independent experiments i.e. replicates with \pm SE. Difference between means obtained was tested by Student's $t$ test at level of significance $-{ }^{\star} p<0.05,{ }^{* *} p<0.01,{ }^{* * *} p<0.001$. For correlation analysis XY scatter charts were prepared and correlation coefficient, 
$\mathrm{R}^{2}$, values are given.

\section{Results and Discussion}

Seed irradiation at $1-10$ Gy doses had no effect on water regain capacity of the seeds soaked in excess of distilled water for $24 \mathrm{~h}$, but significantly reduced the total acid phosphatase activity exerting a strong -ve correlation with $\mathrm{R}^{2}$ value of 0.685 (Table 1). However, decrease in specific activity was not significant though a strong -ve correlation with $\mathrm{R}^{2}$ value of 0.725 was observed.

Seed irradiation at doses 0.5, 2.0 and 5.0 Gy affected \% germination, germination index, seedling wt and vigour in 4 days old bean seedlings depending upon the dose. All these parameters remained unaffected at $0.5 \mathrm{~Gy}$ but reduced at $5 \mathrm{~Gy}$ with most prominent effect for seedling vigour (Table 2). However, at 2.0 Gy dose, \% germination and germination index were increased, seedling wt was decreased and seedling vigour remained unaffected.

Table 1. Effect of seed irradiation on water content and acid phosphatase activity in soaked seeds, 10 seeds each of irradiated doses were soaked in excess of distilled water for $24 \mathrm{~h}$ and the soaked seeds were analysed for various parameters.

\begin{tabular}{|c|c|c|c|}
\hline $\begin{array}{l}\text { Irradiation } \\
\text { Dose, Gy }\end{array}$ & $\begin{array}{l}\text { Water regain, } \mathrm{mg}^{-1} \mathrm{~g}^{-1} \\
\text { dry seeds }\end{array}$ & $\begin{array}{l}\text { Acid phosphatase, } \\
\qquad \mathrm{g}^{-1} \text { fr wt }\end{array}$ & $\begin{array}{c}\mu \mathrm{g} \text { p nitrophenol } \mathrm{min}^{-1} \\
\mathrm{mg}^{-1} \text { protein }\end{array}$ \\
\hline 0 & $1.09(100)$ & $1687 \pm 223(100)$ & $36 \pm 4(100)$ \\
\hline 1 & $1.10(101)$ & $1102 \pm 355(65)$ & $40 \pm 14(111)$ \\
\hline 3 & $1.10(101)$ & $1044 \pm 181^{*}(62)$ & $38 \pm 9(106)$ \\
\hline 8 & $1.10(101)$ & $776 \pm 100^{\star *}(46)$ & $34 \pm 6(94)$ \\
\hline 10 & $1.12(101)$ & $802 \pm 156^{*}(48)$ & $26 \pm 5(72)$ \\
\hline $\mathbf{R}^{2}$ & 0.656 & 0.685 & 0.702 \\
\hline
\end{tabular}

Values relative to control are given in parentheses. Level of significance: ${ }^{\star} p$ value $<0.05,{ }^{* *} p$ value $<0.01$.

Table 2. Effect of seed irradiation on short term growth of the seedlings. Fifteen seeds each of irradiated doses were raised for 4 days in continuous light in petri plates having filter paper moistened with distilled water and growth of the developing seedlings measured as wt\% germination, MGT and vigour of the seedlings was analysed.

\begin{tabular}{ccccc}
\hline $\begin{array}{c}\text { Irradiation } \\
\text { Dose, Gy }\end{array}$ & Germination, \% & $\begin{array}{c}\text { Germination } \\
\text { Index }\end{array}$ & Seedling wt, g & $\begin{array}{c}\text { Seedling vigour \% } \\
\mathrm{G}^{*} \mathrm{Wt}\end{array}$ \\
\hline 0.0 & $72 \pm 6(100)$ & $10.9 \pm 1.3(100)$ & $0.80 \pm 0.02(100)$ & $58(100)$ \\
0.5 & $75 \pm 10(104)$ & $10.1 \pm 1.3(93)$ & $0.79 \pm 0.07(99)$ & $59(102)$ \\
2.0 & $82 \pm 3(114)$ & $12.8 \pm 0.9(117)$ & $0.69 \pm 0.02(86)$ & $57(98)$ \\
5.0 & $68 \pm 7(94)$ & $9.8 \pm 0.9(90)$ & $0.74 \pm 0.05(93)$ & $50(86)$ \\
$\mathbf{R}^{2}$ & $\mathbf{0 . 1 4 8}$ & $\mathbf{0 . 0 5 3}$ & $\mathbf{0 . 3 0 0}$ & $\mathbf{0 . 9 2 4}$
\end{tabular}

Values relative to control are given in parentheses. 
Synchroton X-ray irradiation of the seeds at 2 and 5 Gy doses substantially reduced the overall growth measured as \% germination, shoot and root length, total length, seedling vigour index (SVI), root and leaf wt in 10 days old seedlings, however, at 0.5 Gy dose, these parameters were marginally affected except \% G and SVI (Table 3(a) and Table 3(b)). Further strong correlation between irradiation dose and growth parameters also resulted with $\mathrm{R}^{2}$ values of $0.754,0.637,0.829,0.862,0.763,0.615$ and 0.711 , respectively. NRA of the developing leaf was significantly reduced in response to irradiation exerting strong correlation having $\mathrm{R}^{2}=0.825$ (Table 3(b)).

Plant exposure to ionizing radiations in the vicinity of nuclear accidents to influence growth and development has been reported [1]. In the present study, impact of x-ray exposure using Phaseolus vulgaris seedlings has been investigated. Although using diagnostic doses of $\mathrm{x}$ rays accelerated growth of Phsaeolus vulgaris [9] and increased root length at $0.05-15 \mathrm{~Gy}$ and leaf wt at low doses in

Table 3. (a) Effect of seed irradiation on long term growth of the seedlings. Twenty five seeds each of irradiated doses were raised in plastic pots containing acid washed sand for 10 days in continuous light and growth of the developing seedlings measured as \% germination, shoot, root and total length and SVI was analysed; (b) Effect of seed irradiation on long term growth of the seedlings. Twenty five seeds each of irradiated doses were raised in plastic pots containing acid washed sand for 10 days in continuous light and growth of the developing seedlings measured as root wt, leaf wt and nitrate reductase activity was analysed.

(a)

\begin{tabular}{cccccc}
\hline $\begin{array}{c}\text { Irradiation } \\
\text { dose, Gy }\end{array}$ & Germination, $\%$ & $\begin{array}{c}\text { Shoot length, } \\
\mathrm{cm}\end{array}$ & $\begin{array}{c}\text { Root length, } \\
\mathrm{cm}\end{array}$ & $\begin{array}{c}\text { Total length, } \\
\mathrm{cm}\end{array}$ & SVI \% G*L \\
\hline 0.0 & $60 \pm 0(100)$ & $16.6 \pm 1.2(100)$ & $17.7 \pm 0.7(100)$ & $34.3(100)$ & $2058(100)$ \\
0.5 & $40 \pm 0^{* *}(67)$ & $18.1 \pm 0.9(109)$ & $15.2 \pm 0.7^{*}(86)$ & $33.3(97)$ & $1332(65)$ \\
2.0 & $30 \pm 0.3^{* *}(50)$ & $13.6 \pm 0.6^{*}(82)$ & $14.1 \pm 1.3^{*}(80)$ & $27.7(81)$ & $838(41)$ \\
5.0 & $21 \pm 0.7^{* * *}(35)$ & $13.4 \pm 0.4^{*}(81)$ & $12.3 \pm 1.9^{*}(69)$ & $25.7(74)$ & $527(26)$ \\
$\mathbf{R}^{2}$ & $\mathbf{0 . 7 5 4}$ & $\mathbf{0 . 6 3 7}$ & $\mathbf{0 . 8 2 9}$ & $\mathbf{0 . 8 6 2}$ & $\mathbf{0 . 7 6 3}$
\end{tabular}

Values relative to control are given in parentheses. Level of significance: ${ }^{*} p$ value $<0.05,{ }^{* *} p$ value $<0.01$, ${ }^{* * *} p$ value $<0.001$.

(b)

\begin{tabular}{cccc}
\hline Irradiation dose, Gy & Root wt, $g$ & Leaf wt, $g$ & $\begin{array}{c}\text { Leaf NRA, nmoles } \\
\mathrm{NO}_{2} \mathrm{~h}^{-1} \mathrm{~g}^{-1} \text { fr wt }\end{array}$ \\
\hline 0.0 & $0.211 \pm 0.02(100)$ & $0.155 \pm 0.02(100)$ & $189 \pm 53(100)$ \\
0.5 & $0.123 \pm 0.03^{*}(58)$ & $0.147 \pm 0.04(110)$ & $123 \pm 57(65)$ \\
2.0 & $0.06 \pm 0.01^{* * *}(28)$ & $0.07 \pm 0.01^{* *}(45)$ & $127 \pm 65(67)$ \\
5.0 & $0.05 \pm 0.01^{* * *}(24)$ & $0.08 \pm 0.01^{* *}(52)$ & $55 \pm 21^{*}(29)$ \\
$\mathbf{R}^{2}$ & 0.615 & 0.711 & 0.825 \\
\hline
\end{tabular}

Values relative to control are given in parentheses. Level of significance: ${ }^{*} p$ value $<0.05,{ }^{* *} p$ value $<0.01$, ${ }^{* *} p$ value $<0.001$. 
date palm [10] have been reported, in the present system morphological and biochemical growth parameters were reduced by irradiation of the seeds prior to seed development. Further, the effect depended on the growth parameter, irradiation dose and developmental stage of the seeds. Thus, phosphate mobilization during seed growth is prominently affected by irradiation, as the acid phosphatase activity is reduced at $1-10$ Gy doses (Table 1). Increased acid phosphatase activity during germination in maize and soybean has been reported [2] [3]. At later stages of development the severity of irradiation effect on growth is more in 10 days old seedlings than in 4 days old seedlings. With younger seedlings the mass, \% germination, GI and seedling vigour were non-significantly decreased at 5 Gy dose only, while in older seedlings, \% germination, lengths, tissue masses and SVI were significantly reduced and exerted strong correlation also (Table 2, Table 3(a) and Table 3(b)). However, in the study using date palm X-ray exposure in the range of $0.05-15$ Gy decreased \% germination, but increased root length [10].

Availability of nitrogen is an important factor limiting plant growth and development. The major inorganic form utilized by the plant is nitrate. Nitrate reductase catalyses the first and rate-limiting step of nitrate assimilation in fungi, algae and higher plants [11] and often limits plant productivity. Environmental stresses also influence the enzyme activity depending upon the plant species, organ and the causative factor. The effect of $x$-ray irradiation on NRA has not been reported yet. Though the increased expression of Ribulose bis phosphate carboxylase and decreased expression of poly (ADP-ribose) polymerase in response to irradiation of dwarf bean plants by $\mathrm{x}$-radiations has been reported [6]. In the present investigation, the nitrate reductase activity of the developing leaves was reduced significantly with perfect correlation in response to irradiation (Table 3). NRA reflects the overall nitrogen status of the plant and high activity may also indicate the involvement of NO signaling. Hence it is likely that in developing leaves in response to irradiation, the process of nitrate assimilation is reduced, but NO signalling is not involved. However, increased NRA and reduced growth of the seedlings upon irradiation and saline stress has been observed (Unpublished data) and suggested the involvement of NO mediated effect, as NR has been reported to mediate the synthesis of NO [5]. Moreover involvement of NO signaling in response to salinity stress has been suggested in bean seedlings based upon reduced growth and increased NRA [12].

\section{Conclusion}

The effect of seed irradiation on growth of the seedlings depends upon the growth status. In the seeds soaked, seed irradiation significantly reduced the acid phosphatase activity with strong correlation between irradiation dose and enzyme activity. In 4 days old seedlings, growth parameters were non-significantly decreased at 5.0 Gy dose only, but in 10 days old seedlings, the overall growth was substantially reduced at 2 and 5 Gy doses. The nitrogen status of the seedlings, reflected by nitrate reductase activity was significantly reduced in response 
to irradiation exerting strong correlation. The results suggest decreased phosphate mobilization in soaked seeds, time dependent decreased growth being more substantial with longer duration and reduced nitrate assimilation due to seed irradiation with Synchroton X-Ray Beam.

\section{Acknowledgements}

The Project Grant to RG and Fellowship to SD by UGC-DAE Consortium for Scientific Research, Indore (CSR-IC-BL24/CRS-121-2014-15/1217 dt 27/3/2015) is acknowledged.

\section{References}

[1] Sidorov, V.P. (1994) Cytogenic Effect in Pinus sylvestris Needle Cells as a Result of the Chernobyl Accident Radiation Biology. Radioecology, 34, 847-851.

[2] Prazeres, J.N., Ferreira, C.V. and Aoyama, H. (2004) Acid Phosphatase Activities during the Germination of Glycine Max Seeds. Plant Physiology and Biochemistry, 42, 15-20. https://doi.org/10.1016/j.plaphy.2003.10.009

[3] Serenna, R., Simonin, V., Silva-Neto, M.A.C. and Fialho, E. (2006) Induction of Acid Phosphatase Activity during Germination of Maize (Zea mays) Seeds. Plant Physiology and Biochemistry, 44, 467-473.

https://doi.org/10.1016/j.plaphy.2006.03.008

[4] Srivastava, H.S. (1980) Regulation of Nitrate Reductase in Higher Plants. Phytochemistry, 19, 725-733. https://doi.org/10.1016/0031-9422(80)85100-4

[5] Rockel, P., Strube, F., Rockel, A., Wildt, J. and Kaiser, W.M. (2002) Regulation of Nitric Oxide Production by Plant Nitrate Reductase in vivo and in vitro. Journal of Experimental Botany, 53, 103-110. https://doi.org/10.1093/jexbot/53.366.103

[6] Arena, C., De Micco, V. and De Maio, A. (2014) Growth Alteration and Leaf Biochemical Responses in Phaseolus vulgaris Exposed to Different Doses of Ionising Radiation. Plant Biology, 16, 194-202. https://doi.org/10.1111/plb.12076

[7] Dhamgaye, V., Lodha, G., Gowri Sankar, B. and Kant, C. (2014) Beamline BL-07 at Indus-2: A Facility for Microfabrication Research. Journal of Synchrotron Radiation, 21, 259-263. https://doi.org/10.1107/S1600577513024934

[8] Srivastava, H.S. (1975) Distribution of Nitrate Reductase in Bean Seedlings. Plant Cell Physiology, 16, 995-999. https://doi.org/10.1093/oxfordjournals.pcp.a075245

[9] Mortzavi, S.M.J., Mehdi-Pour, L.A., Tanavardi, S., Mohammadi, S., Kazempour, S., Fatehi, S., Behnejad, B. and Mozdarani, H. (2006) The Biopositive Effects of Diagnostic Doses of X-Rays on Growth of Phaseolus vulgaris Plant : A Possibility of New Physical Fertilizers. Asian Journal of Experimental Sciences, 20, 27-33.

[10] Al-Enezi, N.A., Al-Bahrany, A.M. and Al-Khayri, J.M. (2012) Effect of X-Irradiation on Date Palm Seed Germination and Seedling Growth. Emirates Journal of Food and Agriculture, 24, 415-424.

[11] Campbell, W.H. (2001) Structure and Function of Eukaryotic NAD(P)H: Nitrate Reductase. Cell Molecular Life Science, 53, 194-204.

https://doi.org/10.1007/PL00000847

[12] Dhamgaye, S. and Gadre, R. (2015) Salinity Stress Effects on Growth and Nitrate Assimilation in Bean Seedlings Likely to Be Mediated via Nitric Oxide. Journal of Stress Physiology and Biochemistry, 11, 137-146. 